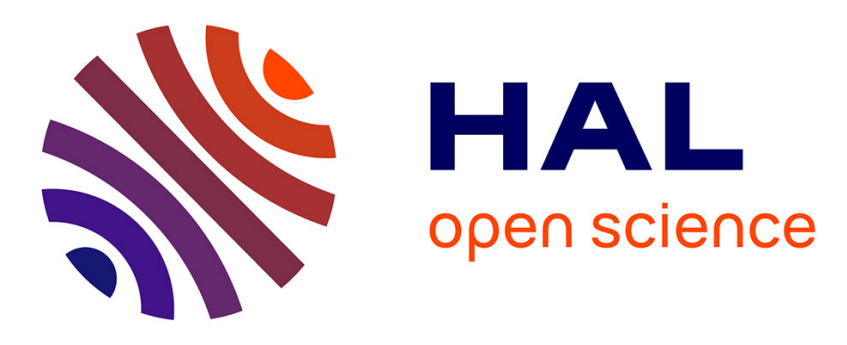

\title{
A New Model for the Plasma Electrons Fluxes (Part of GREEN Model)
}

Angélica Sicard, Daniel Boscher, Didier Lazaro, Sébastien Bourdarie, Denis

Standarovski, Robert Ecoffet

\section{- To cite this version:}

Angélica Sicard, Daniel Boscher, Didier Lazaro, Sébastien Bourdarie, Denis Standarovski, et al.. A New Model for the Plasma Electrons Fluxes (Part of GREEN Model). IEEE Transactions on Nuclear Science, 2019, 66 (7), pp.1738-1745. 10.1109/TNS.2019.2923005 . hal-02315476

\author{
HAL Id: hal-02315476 \\ https://hal.science/hal-02315476
}

Submitted on 14 Oct 2019

HAL is a multi-disciplinary open access archive for the deposit and dissemination of scientific research documents, whether they are published or not. The documents may come from teaching and research institutions in France or abroad, or from public or private research centers.
L'archive ouverte pluridisciplinaire HAL, est destinée au dépôt et à la diffusion de documents scientifiques de niveau recherche, publiés ou non, émanant des établissements d'enseignement et de recherche français ou étrangers, des laboratoires publics ou privés. 


\title{
A new model for the plasma electrons fluxes (part of GREEN model)
}

\author{
A. Sicard, D. Boscher, D. Lazaro, S. Bourdarie, D. Standarovski, R. Ecoffet
}

\begin{abstract}
A new specification model of low energy electrons fluxes, included in GREEN model, has been developed at ONERA. This model is based on several data sets, from low altitudes with NOAA-POES measurements to higher altitudes with POLAR, THEMIS and LANL measurements. It provides mean electron fluxes versus $L, B / B_{\text {eq }}, M L T$ and energy (for energies between $0.19 \mathrm{keV}$ and few $10 \mathrm{~s}$ of $\mathrm{keV}$ ). In this paper, the model is compared to AE9/SPM model and Van Allen Probe measurements.
\end{abstract}

Index Terms_-plasma, specification model.

\section{INTRODUCTION}

$\mathrm{T}$ HE space environment is composed of charged particles: electrons and ions (mainly protons). These particles induce effects on materials used in space systems like the well-known ones of high energy particles $(>30 \mathrm{keV})$ on electronic devices. But high-energy particles are not the only population to consider. Indeed lower-energy particles $(<30$ $\mathrm{keV}$ ) can create significant damages on surface materials used in space systems (thermal coatings, cover glass ...). Those effects are cumulative such as the relevant radiation environment specification is the total fluence of low-energy particles over the entire mission. Currently, the model available to evaluate this low-energy population is part of AE9/AP9 models and is called SPM [1][2]. This empirical model is mainly based on POLAR/CAMMICE, POLAR/MICS and LANL/MPA data and provides electron fluxes in the energy range $1 \mathrm{keV}-40 \mathrm{keV}$ and proton fluxes in the energy range $1 \mathrm{keV}-164 \mathrm{keV}$. While the original CAMMICE/MICS model [2] was MLT (Magnetic Local Time) dependent the plasma model included in AE9/AP9/SPM is not.

Because SPM model relies only on POLAR data for locations inside GEO, and though POLAR orbit has not sampled all L, $\mathrm{B} / \mathrm{B}_{\text {eq }}$ and MLT we investigate how recent data would improve

This work was supported by CNES, the French Space Agency (R-S18/MT0003-176).

A. Sicard is with ONERA/DPHY, Université de Toulouse, Toulouse, France, (phone: +33-5-61-25-28-81; e-mail: angelica.sicard@onera.fr).

D. Boscher is with ONERA/DPHY, Université de Toulouse, Toulouse, France, e-mail: daniel.boscher@onera.fr).

D. Lazaro is with ONERA/DPHY, Université de Toulouse, Toulouse, France, didier.lazaro@onera.fr).

S. Bourdarie is with ONERA/DPHY, Université de Toulouse, Toulouse, France, e-mail: sebastien.bourdarie@onera.fr).

D. Standarovski is with CNES, The French Space Agency, Toulouse, France, (email: denis.standarovski@cnes.fr)

R. Ecoffet is with CNES, The French Space Agency, Toulouse, France, (email: robert.ecoffet@cnes.fr) such a model. Thus, a new empirical model of low-energy plasma, based on THEMIS, POLAR, NOAA-POES and LANL data, has been developed. As described above, each data set has been analyzed in several dimensions: $\mathrm{L}$ between 3 and 10 with a resolution of 0.2 , MLT with a resolution of 1 hour and energy between 0.19 and $30 \mathrm{keV}$ with five energy channels $0.19 \mathrm{keV}, 0.84 \mathrm{keV}, 2.6 \mathrm{keV}, 8 \mathrm{keV}$ and $30 \mathrm{keV}$. These data are analyzed, cross-calibrated, put together and parametric fits are calculated to provide pitch angle distribution. In this paper the model thus obtained for electrons from energy $>0.1 \mathrm{keV}$ to energy $>30 \mathrm{keV}$ is presented and compared to AE9/AP9/SPM model and validated with Van Allen Probe data. Note that this low energy electron model is not solar cycle dependent. This low-energy electron model is a part of the GREEN (Global Radiation Earth ENvironement) model [3].

\section{DATA USED}

\section{A. Low Earth Orbit Data}

At LEO orbit, NOAA-POES spacecraft (POES-15, POES16, POES-17, POES-18 and POES-19) measurements have been used for two reasons. First, thanks to the POES spacecraft fleet, long term data are available since 1998 with the same detectors TED and MEPED, which are part of SEM2 suite of instrument [4]. From the POES/SEM2 database, four electron channels from TED instrument, $0.19 \mathrm{keV}, 0.84 \mathrm{keV}$, $2.6 \mathrm{keV}$ and $8 \mathrm{keV}$, and one electron channel from MEPED instrument, $>30 \mathrm{keV}$, were considered. Fig. 1 shows the time evolution of $0.19 \mathrm{keV}$ electron flux seen by five POES spacecraft for $4.6<\mathrm{L}<4.8$ and $10 \mathrm{~h}<\mathrm{MLT}<11 \mathrm{~h}$. Some doubt exist on the TED electron channels efficiencies that degrade over time. In this case, the TED flux intensities would slowly decrease over time with periodic increases when the electron channels voltages are adjusted to compensate for the degradation. Fig. 1 indicates that such a behavior is not clearly seen in the data.

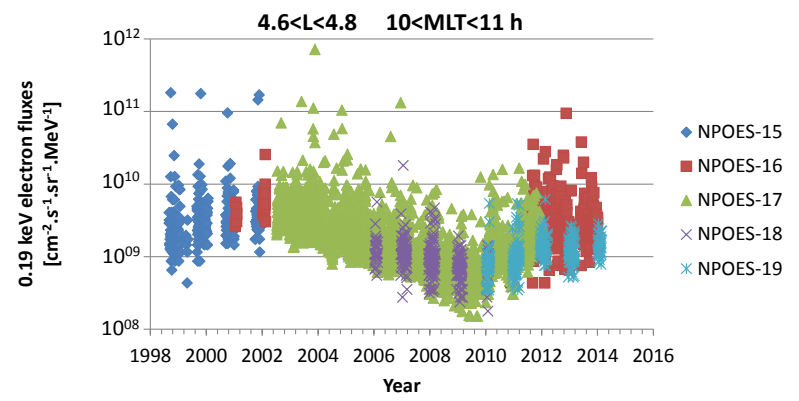

Fig. 1 : Evolution of $0.19 \mathrm{keV}$ electron flux $\left[\mathrm{cm}^{-2} \cdot \mathrm{s}^{-1} \cdot \mathrm{sr}^{-1} \cdot \mathrm{MeV}^{-1}\right]$ versus time measured by five POES spacecraft for $4.6<\mathrm{L}<4.8$ and $10 \mathrm{~h}<\mathrm{MLT}<11 \mathrm{~h}$. 
Moreover during overlaps from one spacecraft to the next no clear discrepancies between data sets are found whereas one would expect them to be larger when one instrument has spent years in space while the other is brand new. In this study the impact of such degradation will be assumed to be negligible.

Electron data have been analyzed and filtered in order to remove bad data.

Fig. 2 shows an example of data filtering applied to POES15/TED $0.84 \mathrm{keV}$ electron channel. In this example one can easily observe a correlation between the $0.84 \mathrm{keV}$ electron fluxes (on the bottom panel) and the $1 \mathrm{MeV}$ electron fluxes measured by POES-15/MEPPED (on the top panel) during the 2004 magnetic storms. As electrons with very low energy do not have the same behavior than high energy electrons, it turns out the $0.84 \mathrm{keV}$ electron channel is contaminated by high energy electron. Cleaning the data is thus essential to obtain a sanitized data set.

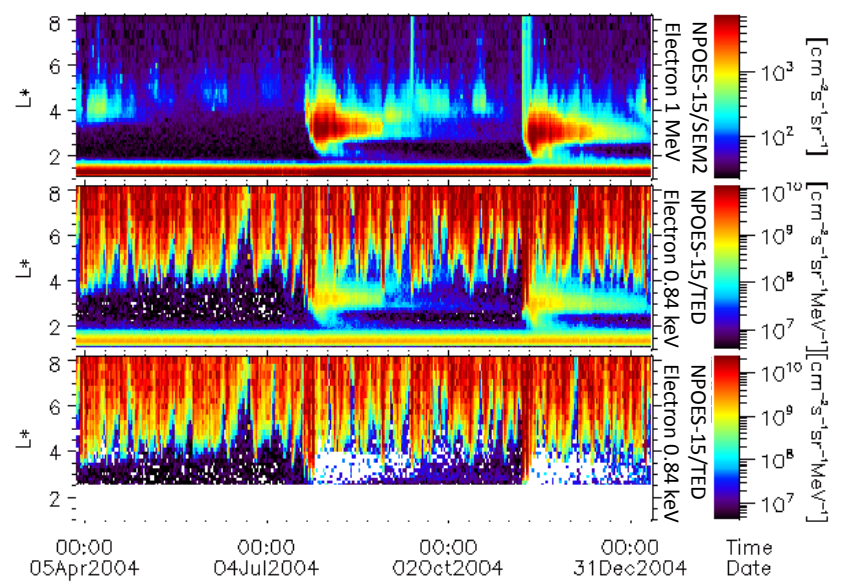

Fig. 2 : L-time cartographies of $0.84 \mathrm{keV}$ electrons flux measured by POES15/TED before cleaning (in the middle), after cleaning (at the bottom) and 1 $\mathrm{MeV}$ electrons flux measured by POES-15/SEM (on the top).

To clean the data, some correlations have been done between POES/TED measurements and high energy electrons measured by POES/SEPEM as plotted on Fig. 3.

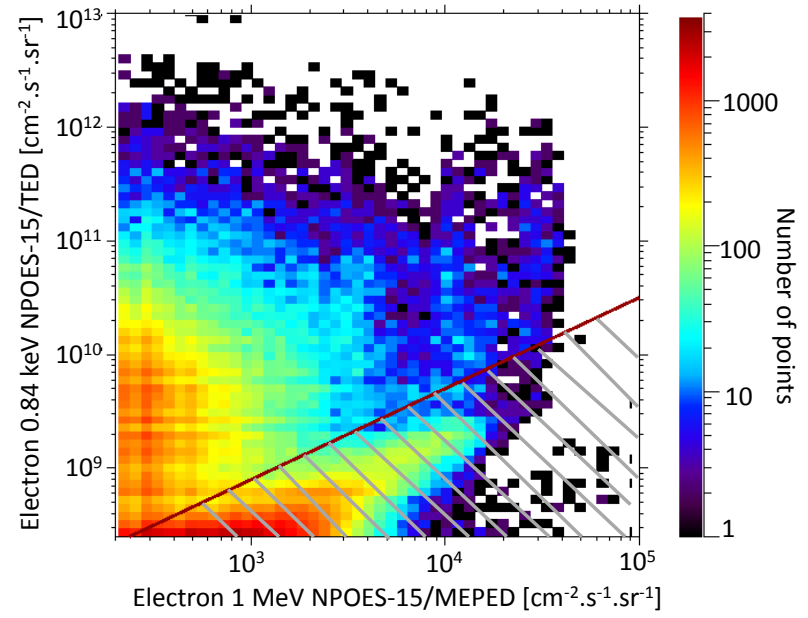

Fig. 3 : Correlation between $0.84 \mathrm{keV}$ electrons flux measured by POES15/TED and $1 \mathrm{MeV}$ electrons flux measured by POES-15/SEM for $2<\mathrm{L}<7$.

The correlation is reflected by the points in the hatched part of the figure. All these points have been removed from the data set. The POES/TED data are also contaminated by high energy protons below $\mathrm{L}=2$. These data are also removed.

The result after the cleaning process is plotted in the bottom panel of Fig. 2. All POES/TED electrons channels are contaminated by high energy electron for $\mathrm{L}>2$ and high energy protons for $\mathrm{L}<2$ and have been cleaned using the same method.

Then, electron data from 1998 to 2018 have been sorted according to magnetic local time (MLT) and L (McIlwain Parameter) as represented on Fig. 4 for two energies: $0.19 \mathrm{keV}$ (on the left) and $8 \mathrm{keV}$ (on the right). A MLT-dependence can be clearly observed in the results, particularly at $8 \mathrm{keV}$ where fluxes are higher in the night side. As data seem to be contaminated for $\mathrm{L}<2$ by high energy protons, this very nearEarth region will not be covered by the model.

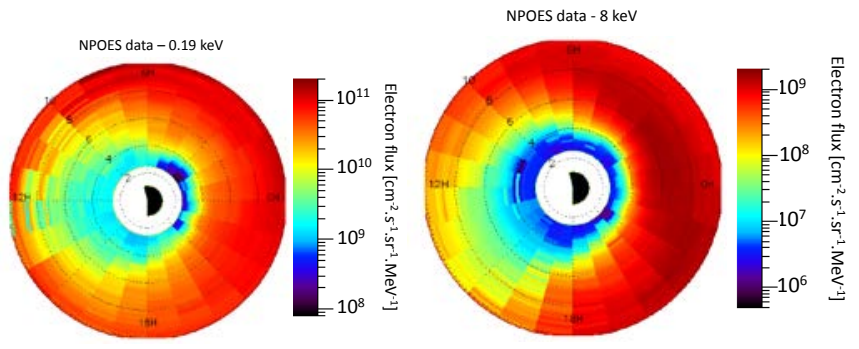

Fig. 4 : Cartographies MLT-L of electrons flux measured by POES/TED from 1998 to 2017 for 2 energies: $0.19 \mathrm{keV}$ and $8 \mathrm{keV}$.

Table 1 resumes the characteristics of data used at LEO. All energy channels mentioned in the third column have been studied and used for each NOAA spacecraft.

TABLE I

CHARACTERISTICS OF DATA USED AT LEO

\begin{tabular}{|c|c|c|}
\hline Spacecraft & Time coverage & Channels \\
\hline POES-15/TED \& MEPED & $07 / 1998 \rightarrow$ now & $0.19 \mathrm{keV}$ \\
POES-16/TED \& MEPED & $10 / 2000 \rightarrow 06 / 2014$ & $0.84 \mathrm{keV}$ \\
POES-17/TED \& MEPED & $07 / 2002 \rightarrow 04 / 2013$ & $2.6 \mathrm{keV}$ \\
POES-18/TED \& MEPED & $06 / 2005 \rightarrow$ now & $8 \mathrm{keV}$ \\
POES-19/TED \& MEPED & $02 / 2009 \rightarrow$ now & $>30 \mathrm{keV}$ \\
\hline
\end{tabular}

Table 1: Characteristics of electron data used at LEO. All energy channel of the third column have been used for each NOAA spacecraft.

\section{B. Data in the magnetosphere}

In order to obtain a global model at low energy up to $\mathrm{L}=10$, data at other orbits than LEO have been taken into account. In this study, data from four other fleets of spacecraft have been used: THEMIS, LANL-GEO spacecraft, Van Allen Probes and POLAR. While the first three fleets have orbits near the equator, POLAR has an elliptical orbit and covers a wider part of the magnetosphere in term of $\mathrm{L}$ and $\mathrm{B} / \mathrm{B}_{\mathrm{Eq}}$. In this study, THEMIS and POLAR data are used to develop the model due to their wide coverage in L and MLT. As it is described in the next part, LANL data are used to calibrate all the data sets between each other. The validation of the model is done thanks to Van Allen Probes data.

THEMIS is a fleet of five spacecraft launched in 2007. Only THEMIS-A, THEMIS-D and THEMIS-E have a time coverage large enough to be used in this study. Data from ESA instrument [5], covering energies between $7 \mathrm{eV}$ and 26 $\mathrm{keV}$, and data from SST instrument covering $26 \mathrm{keV}$ to 200 $\mathrm{keV}$ were investigated. As for POES data contamination by high energy electrons has been identified. The best way to 
clean ESA data by removing contaminated data would be to correlate ESA data with high energy measurements on the same spacecraft, that is to say on THEMIS/SST. However the higher energy measured on SST is $700 \mathrm{keV}$, which is not high enough to have a good correlation with ESA data as it can be observed on Fig. 5. Moreover Fig. 5 shows also that THEMIS/SST data are saturated. That's why we choose to correlate THEMIS/ESA data with high energy electron measurements on POES-15. This correlation is not a time to time correlation due to the difference of orbit between THEMIS and POES-15 but it is the best way we found to clean this data set. All THEMIS/ESA channels have been cleaned in the same way. As for POES /TED data, THEMIS/ESA data are contaminated by high energy proton below $\mathrm{L}<2.2$. These data have also been filtered.

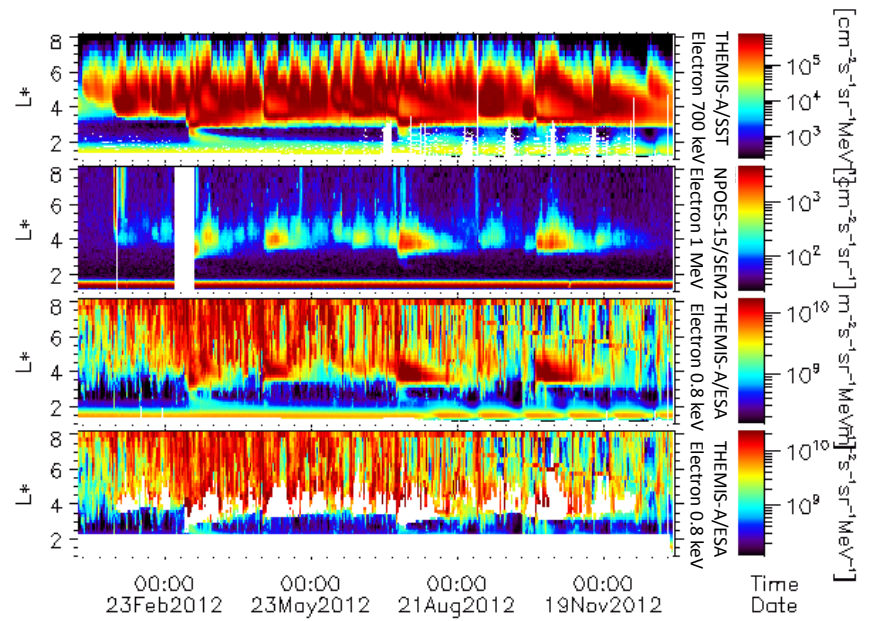

Fig. 5 : L-time cartographies of $700 \mathrm{keV}$ electrons measured by THEMIS/SST (on the top), $1 \mathrm{MeV}$ electrons flux measured by POES-15/SEM (second panel), $0.8 \mathrm{keV}$ electrons flux measured by THEMIS-A/ESA before cleaning (third panel), after cleaning (at the bottom).

The white color near $\mathrm{L}=4$ on Fig. 5 shows that many measurements are filtered due to contamination. In this study the long-term mean flux is calculated by averaging all the non contaminated measurements. Thus, a question arises: how this cleaning procedure affects the long-term mean flux? To answer this question, we have calculated the averaged flux on a calm period without contamination (in 2009) at $\mathrm{L}=4$ to obtain a reference value. Then, we have calculated the longterm (2008-2016) mean flux at $\mathrm{L}=4$ by averaging all the measurements, the contaminated ones being set artificially to the averaged flux in calm period in 2009. At $\mathrm{L}=4$, over the period 2008-2016, the ratio between mean flux without contaminated measurements and the mean flux with the contaminated measurements set to averaged flux during calm period is a factor 1.5. But this does not mean that the model developed here will overestimate flux by a factor 1.5 at $\mathrm{L}=4$ because the real mean flux would probably be between the both values. We decided to use the higher value to be conservative.

Then electron data from 2008 to 2015 have been sorted according to MLT and L as represented on Fig. 6 at two energies: $0.19 \mathrm{keV}$ (on the left) and $8 \mathrm{keV}$ (on the right). On the $0.19 \mathrm{keV}$ map, the magnetosheath at $\mathrm{L}>8$ on the day side can be clearly observed. As for POES data, THEMIS data are contaminated at $\mathrm{L}<2.2$ by energetic protons.

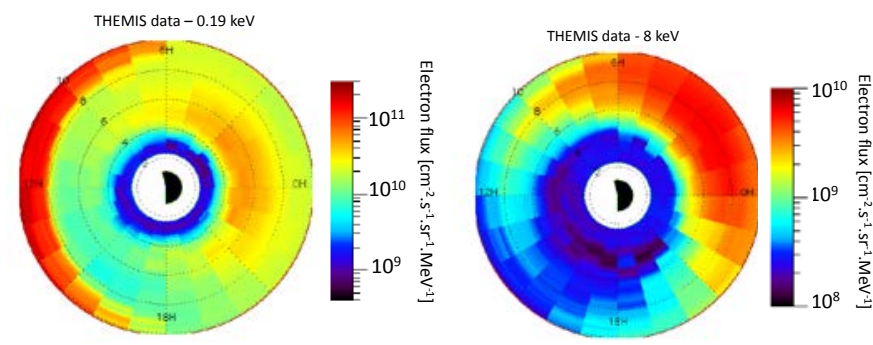

Fig. 6 : MLT-L cartographies of electrons flux measured by THEMIS/ESA from 2008 to 2015 for 2 energies: $0.19 \mathrm{keV}$ and $8 \mathrm{keV}$.

POLAR was launched in 1996 on an elliptical orbit with several instruments on-board including HYDRA [6], a detector measuring electrons and protons from $12 \mathrm{eV}$ to 18 $\mathrm{keV}$. Due to its orbit and in contrast to the two previous spacecraft fleets, POLAR data cover not only the equator as THEMIS, or only the highest latitudes as POES but also intermediate regions. POLAR data have been analyzed in detail as well and some periods when measurements are suspicious have been removed. Contamination by high energy electrons has been filtered out following the same strategy as for POES spacecraft using high energy electron data on POLAR/CEPPAD (Fig. 7).

Then POLAR data have been sorted in three classes according to the equatorial pitch angle $\alpha_{\mathrm{eq}}\left(\alpha_{\mathrm{eq}}=\mathrm{asin}\left(\sqrt{ }\left(\mathrm{B}_{\mathrm{eq}} / \mathrm{B}\right)\right.\right.$, with $\mathrm{B}_{\mathrm{eq}}$ the equatorial magnetic field and $\mathrm{B}$ the local magnetic field) deduced from the spacecraft position along the field line: $\alpha_{\mathrm{eq}}<30^{\circ}$ (high latitude), $30^{\circ}<\alpha_{\mathrm{eq}}<60^{\circ}$ and $\alpha_{\mathrm{eq}}>60^{\circ}$ (near equator).

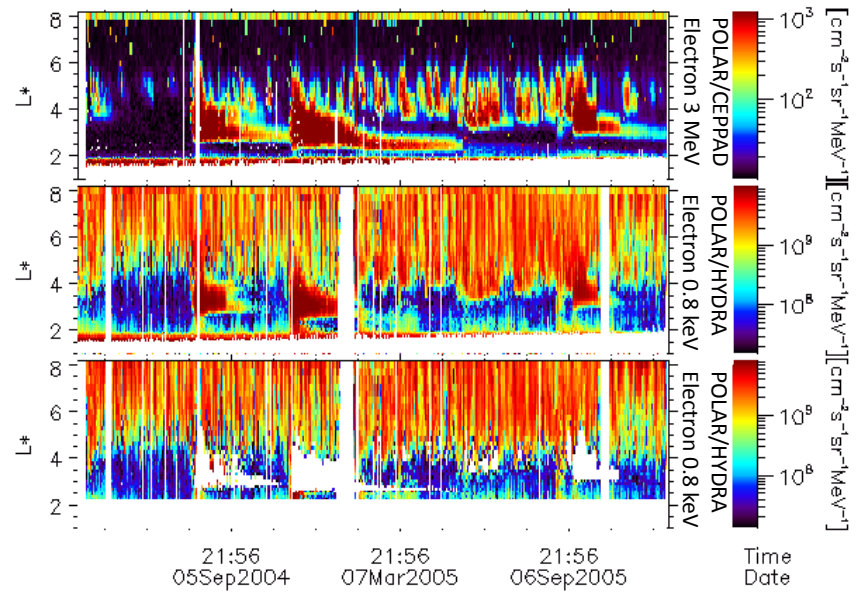

Fig. 7 : L-time cartographies of $0.8 \mathrm{keV}$ electrons flux measured by POLAR/HYDRA before cleaning (in the middle), after cleaning (at the bottom) and $1 \mathrm{MeV}$ electrons flux measured by POES-15/SEM (on the top).

Fig. 8 represents MLT-L cartographies of fluxes measured by POLAR/HYDRA from 1998 to 2008 for $8 \mathrm{keV}$ electrons near the equator $\left(\alpha_{\mathrm{eq}}>60^{\circ}\right)$ on the right and at high latitudes $\left(\alpha_{\mathrm{eq}}<30^{\circ}\right)$ on the left. These plots indicate that there is a dependence of low energy electron fluxes with latitude. Moreover, comparing the cartography from POLAR (on the right) to the one from THEMIS (Fig. 6) in the equatorial region, $8 \mathrm{keV}$ electron fluxes from POLAR are a little bit lower than those from THEMIS. A data cross-calibration is necessary and the procedure will be described in the next section of this paper. 


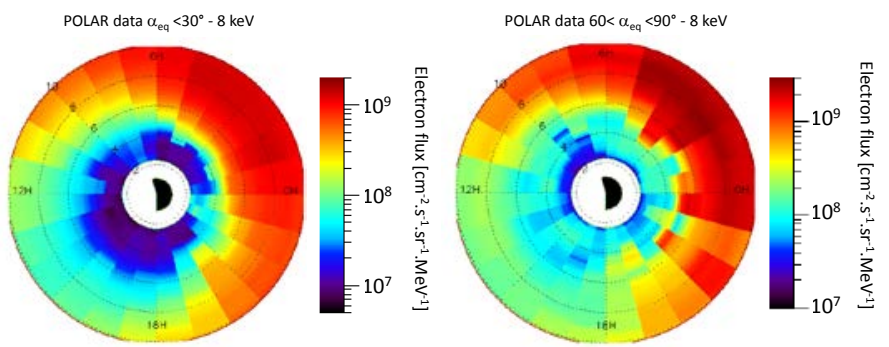

Fig. 8 : MLT-L cartographies of flux measured by POLAR/HYDRA from 1998 to 2008 for $8 \mathrm{keV}$ electrons near the equator (on the left) and at high latitudes (on the right).

Los Alamos National Laboratory (LANL) has a fleet of many spacecraft at geostationary orbit since 1976 with several particle detectors on-board including MPA instrument (Magnetospheric Plasma Analyser) [7] measuring electrons from $100 \mathrm{eV}$ to $34 \mathrm{keV}$. Taking into account the very good quality of these data but the narrow coverage in L, they have only been used to cross-calibrate the data sets together (see section III-A). Note that data from all LANL spacecraft (from 1989-046 to LANL_02A) have been investigated.

Van Allen Probes A and B have been launched in 2012 on an equatorial orbit between $500 \mathrm{~km}$ and $30600 \mathrm{~km}$. The on-board plasma instrument HOPE [8] is measuring electrons from 15 $\mathrm{eV}$ to $50 \mathrm{keV}$. Note that the release 3 of the data has been used. It was decided to validate the model against Van Allen probes HOPE data.

Table 2 resumes the characteristics of the entire electron data sets used in this study at other orbits than LEO.

TABLE II

CHARACTERISTICS OF DATA USED AT OTHER ORBITS

\begin{tabular}{|c|c|c|}
\hline $\begin{array}{c}\text { Satellite/ } \\
\text { Instrumentt }\end{array}$ & Time coverage & Channels used \\
\hline POLAR/HYDRA & $01 / 1998 \rightarrow 03 / 2008$ & $\begin{array}{c}29 \text { channels between } 12 \\
\mathrm{eV} \text { and } 18 \mathrm{keV}\end{array}$ \\
\hline POLAR/CEPPAD & $01 / 1998 \rightarrow 03 / 2008$ & $\begin{array}{c}7 \mathrm{channels} \text { between } 19 \\
\mathrm{keV} \text { and } 212 \mathrm{keV}\end{array}$ \\
\hline THEMIS/ESA & $01 / 2008 \rightarrow 12 / 2015$ & $\begin{array}{c}21 \mathrm{channels} \text { between } 7 \\
\mathrm{eV} \text { and } 26 \mathrm{keV}\end{array}$ \\
\hline THEMIS/SST & $01 / 2008 \rightarrow 12 / 2015$ & $\begin{array}{c}7 \mathrm{channels} \text { between } 31 \\
\mathrm{keV} \text { and } 200 \mathrm{keV}\end{array}$ \\
\hline LANL/MPA & $01 / 1998 \rightarrow 11 / 2005$ & $\begin{array}{c}23 \mathrm{channels} \text { between } 100 \\
\mathrm{eV} \text { and } 34 \mathrm{keV}\end{array}$ \\
\hline LANL/SOPA & $01 / 1998 \rightarrow 11 / 2005$ & $\begin{array}{c}4 \mathrm{channels} \text { between } 50 \\
\mathrm{keV} \text { and } 250 \mathrm{keV}\end{array}$ \\
\hline VAP/HOPE & $01 / 2013 \rightarrow 01 / 2018$ & $\begin{array}{c}72 \mathrm{channels} \text { between } 15 \\
\mathrm{eV} \text { and } 50 \mathrm{keV}\end{array}$ \\
\hline VAP/MAGEIS & $01 / 2013 \rightarrow 01 / 2018$ & $\begin{array}{c}7 \mathrm{channels} \text { between } 32 \\
\mathrm{keV} \text { and } 226 \mathrm{keV}\end{array}$ \\
\hline
\end{tabular}

Table 2: Characteristics of electron data used at other orbits. Data sets in light grey are used to develop the model. Data sets in medium grey are used to calibrate data. Data sets in dark grey is used to validate the model.

\section{MODEL DEVELOPMENT}

\section{A. Data sets cross-calibration}

In order to have coherent data sets to develop an empirical specification model, their cross calibrations are essential. First, all the data sets have been interpolated in energy in order to obtain the same five energy channels as POES data. (0.19, $0.84,2.6,8 \mathrm{keV}$ and $>30 \mathrm{keV}$ ). Then, the standard way to cross-calibrate data independent sensors is through the comparison of fluxes during magnetic conjunction, that is to say when both sensors are "close" in terms of L, MLT, time and during quiet magnetic activity. To do this we need a reference data set. In our case we choose to use LANL/MPA data as a reference [5]. This data set has been studied and used many times to develop empirical models [1][2][9]. However, it is important to discuss about how the LANL-GEO frame charging affects the fluxes. These data have already been studied in terms of spacecraft potential effects and it is possible to correct electron flux according to this potential and the Liouville's theorem [10][11]. Just to keep in mind, the long-term mean electron flux at $0.19 \mathrm{keV}$ at GEO orbit is 1.5 higher when the correction from the spacecraft potential is applied than without the correction. For higher energy the correction has no influence on the mean flux. In order to be sure that the data used in this study are as close as possible to reality, the correction has been applied.

However, LANL/MPA data are only available up to November 2005. So it is impossible to get conjunction between LANL and THEMIS due to the time coverage of THEMIS data. Consequently, in order to cross-calibrate all our data sets used in this study in the same way, we decided to use another method. It has been shown in previous studies that a correlation exists between fluxes at high latitudes (LEO orbit) and at the equator in the radiation belts [12]. So, two reference data sets are chosen, one near equator (equatorial pitch angle $>70^{\circ}$ ), from LANL spacecraft, and one at LEO, from POES spacecraft. Then, the goal is to calculate the factor between fluxes at LEO (POES) and those near equator (LANL for equatorial pitch angle $>70^{\circ}$ ) and for nearly the same MLT, $\mathrm{L}$ and time for the two data sets mentioned just above and during quiet magnetic period. The following conditions have been used: $-3 \mathrm{~h}<\mathrm{MLT}<3 \mathrm{~h}$ (with $\triangle \mathrm{MLT}<1 \mathrm{~h}$ between the two data sets), $6.2<\mathrm{L}<7.2$ (with $\Delta \mathrm{L}<0.2$ ), $\Delta \mathrm{t}<24 \mathrm{~h}$ and $\mathrm{Kp}<2$ during two days before. Then a mean factor for each of the 5 energies $(0.19,0.84,2.6,8 \mathrm{keV}$ and $>30 \mathrm{keV})$ is calculated and is our reference. The same calculation is done using THEMIS and then using POLAR data instead of LANL data. Considering the same range of MLT, L, pitch angle and Kp conditions, the factor between electrons fluxes at LEO and near equator should be the same than the reference factors calculated with LANL data. If it is not the case, a correction will be apply to POLAR and THEMIS data in order to be consistent with POES and LANL data which are our references.

Table 3 presents the correction factors to apply to POLAR and THEMIS data for each energy channel obtained using the method described above.

TABLE III

CORRECTION FACTORS TO APPLY TO POLAR AND THEMIS DATA

\begin{tabular}{|c|c|c|c|c|c|}
\hline & $\begin{array}{c}0.19 \\
\mathrm{keV}\end{array}$ & $0.84 \mathrm{keV}$ & $\begin{array}{c}2.6 \\
\mathrm{keV}\end{array}$ & $8 \mathrm{keV}$ & $>30 \mathrm{keV}$ \\
\hline THEMIS & 1.01 & 0.78 & 0.821 & 0.96 & 1.0 \\
\hline POLAR & 2.71 & 2.29 & 2.79 & 1.36 & 5.15 \\
\hline
\end{tabular}

Table 3: Correction factors to apply to THEMIS and POLAR data sets using LANL and POES data as references.

It is important to note that the correction factors for THEMIS data are close to one, which proves that THEMIS and LANL data are coherent with each other although they do not have a 
common time range (2008-2015 for THEMIS against 19982005 for LANL). However, although having a common time period with LANL, the POLAR data appear to be a little bit too low the correction factor being greater than 1 .

\section{B. How to take into account the limited time period of most of the data sets?}

In a first step the solar cycle variation will not be included in the model. So it is essential to take into account the different time coverage of the data sets being used in this study according to the solar cycle. Indeed, POES data cover two solar cycles while THEMIS and POLAR data cover only one solar cycle with a partial MLT coverage at each time. Taking into account the flux modulation as seen on Fig. 1, it is necessary to calculate a correction factor to apply to THEMIS and POLAR data which will account for their solar cycle fraction of availability at each $\mathrm{L}, \mathrm{B} / \mathrm{B}_{\mathrm{Eq}}$, and MLT. It is important to keep in mind that this low energy model (which is a part of GREEN) is a mean model to be used for long duration mission. Thus, mean fluxes over the longest time period as possible are expected to be more representative.

In order to calculate this correction factor, ratios between the mean POES flux over the time period 1998-2018 and the mean POES flux over THEMIS time period (2008-2015) on one side and POLAR time period (1998-2008) on the other side, shall be computed for each energy, each $L$ and each MLT values. These ratios correspond to the difference of long term dynamics of electron to shorter term time periods. The factors applied to THEMIS and POLAR are then defined as follow:

Corr. factor $(E c, L, M L T)=\frac{\text { Mean POES flux }(E c, L, M L T) \text { between } 1998 \text { and } 2018}{\text { Mean POES flux }(E c, L, M L T) \text { during s/c period }}$

These correction factors are applied to THEMIS and POLAR electron fluxes, for each energy, L and MLT in order to harmonize data sets representativity with the long term POES data (1998-2018). The values of these factors (versus Ec, L and MLT) are not fully described here but one should note that they range between 0.5 and 1 for POLAR time period and between 1 and 2.5 for THEMIS time period. It means that in the region between $\mathrm{L}=3$ and $\mathrm{L}=10$, electron fluxes measured by POES and averaged on the time period of POLAR data considered in this study (1998-2008) are higher than the same fluxes averaged over the two solar cycles of POES data (19982017). On the contrary electron fluxes measured by POES and averaged over the time period of THEMIS data considered in this study (2008-2015) are lower than the same fluxes averaged over the two solar cycles of POES data (1998-2017). Assuming this tendency at LEO is also true at other orbits, POLAR data have to been lowered and THEMIS data have to be increased to provide an accurate and representative long term mean flux.

\section{Variation of electron flux along magnetic field lines}

The third step in the development of the model is to find a general fit, for each $\mathrm{L}$ bin (from $\mathrm{L}=3$ to $\mathrm{L}=10$ ), MLT and energy, allowing to calculate mean electron fluxes everywhere along a magnetic field line based on the data sets in use in this study. First, because fluxes provided by the existing GREEN model are fluxes integrated in energy, all data described before have been converted into five integrated channels: $>0.19 \mathrm{keV},>0.84 \mathrm{keV},>2.6 \mathrm{keV},>8 \mathrm{keV}$ and $>30 \mathrm{keV}$. Then, taking into account the contamination of the data used to develop the low energy plasma model below $\mathrm{L}=2$ or 2.2 (according to data sets), we decided to construct a model between $\mathrm{L}=3$ and $\mathrm{L}=10$ to be sure of the provided flux.

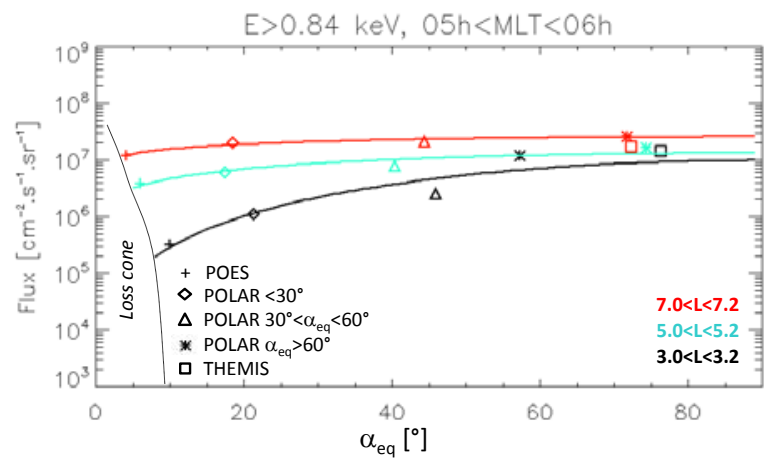

Fig. 9 : Electron flux along a field line versus equatorial pitch angle for $\mathrm{E}>0.84 \mathrm{keV}$ and $0 \mathrm{~h}<\mathrm{MLT}<1 \mathrm{~h}$. The points correspond to spacecraft data (after correction factors) and the color lines correspond to the best fit for three $\mathrm{L}$ bin for a given energy and a given MLT.

Thus, Fig. 9 presents an example of electrons flux along a field line versus equatorial pitch angle for three $L$ values: 3 . $0<\mathrm{L}<3.2,5.0<\mathrm{L}<5.2$ and $7.0<\mathrm{L}<7.2$, for $\mathrm{E}>0.84 \mathrm{keV}$. The points correspond to spacecraft data (after applying correction factors) and the color lines correspond to the best fit, of the form $\mathrm{Y}=\exp \left(\mathrm{A} \cdot \sin ^{\mathrm{B}}(\mathrm{X})\right.$ ), for these three $\mathrm{L}$ bins and the given energy and MLT. This fit is the same as the one used in the SLOT model [14].
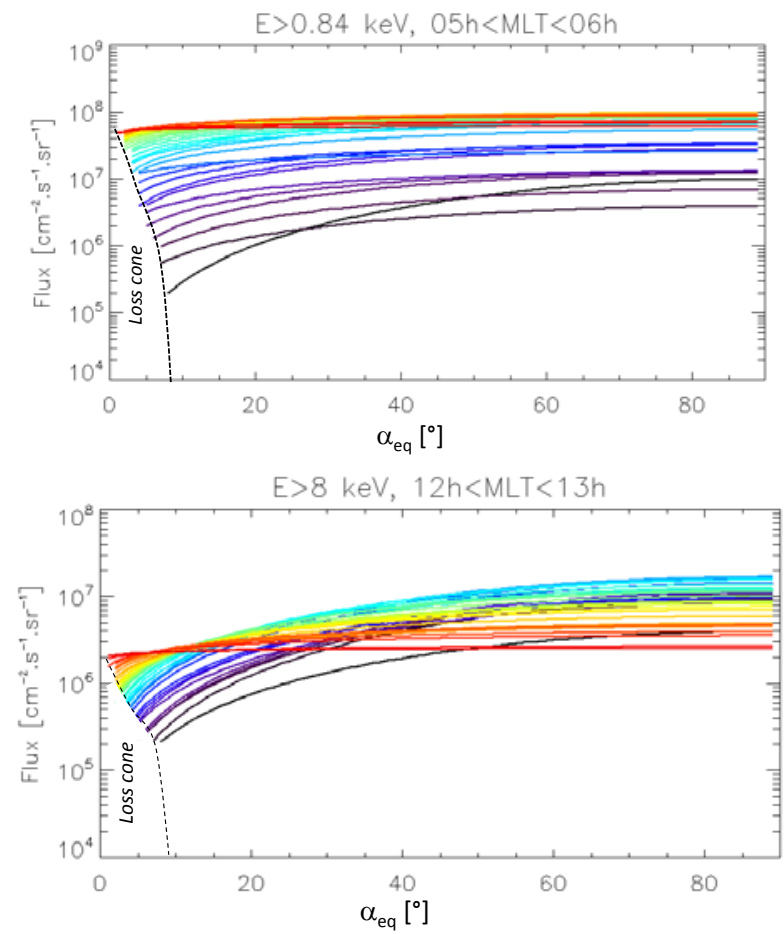

Fig. 10 : Electron flux along a field line versus equatorial pitch angle for $\mathrm{E}>0.84 \mathrm{keV}$ and $6 \mathrm{~h}<\mathrm{MLT}<7 \mathrm{~h}$ on the top and $\mathrm{E}>8 \mathrm{keV}$ and $12 \mathrm{~h}<\mathrm{MLT}<13 \mathrm{~h}$ at the bottom for each $\mathrm{L}$ bin ( 40 bins from $2.0<\mathrm{L}<2.2$ in black to $9.8<\mathrm{L}<10.0$ in red). 
Then, Fig. 10 represents examples of electron fluxes versus equatorial pitch angle for each $\mathrm{L}$ bin considered in this study (35 bins from $3.0<\mathrm{L}<3.2$ in black to $9.8<\mathrm{L}<10.0$ in red), for $\mathrm{E}>0.84 \mathrm{keV}$ and $6 \mathrm{~h}<\mathrm{MLT}<7 \mathrm{~h}$, on the top and $\mathrm{E}>8 \mathrm{keV}$ and $12 \mathrm{~h}<\mathrm{MLT}<13 \mathrm{~h}$ at the bottom. The color lines, correspond to the best fits for each L interval as plotted on Fig. 9 for the given energy and MLT plotted.

The top panel of Fig. $10(\mathrm{E}>0.84 \mathrm{keV})$ indicates that electron fluxes increase along the field line at all $\mathrm{L}$ values, and increase with $\mathrm{L}$. However, the variation between equator and high latitudes is clearly higher for low $\mathrm{L}$ values (black curve) than for high L values (red curve). On the bottom panel, it is quite different because, as seen on Fig. 10, near equator fluxes at low $\mathrm{L}$ values are higher than those at high $\mathrm{L}$ values while at high latitudes fluxes increase with L. This difference between the two plots cannot only be attributed to the difference in energy but also to the different MLT plotted here. The behavior of low energy electron flux is energy and MLT dependent.

\section{Mean electron model with MLT dependence}

Using the fits determined for each of the 4 energies studied, each $L$ interval (30 linear intervals from $L=3$ to 10 ) and each MLT interval (24 linear intervals), electron fluxes from $>0.19$ $\mathrm{keV}$ to $>30 \mathrm{keV}$ can be calculated anywhere in the inner magnetosphere, taking into account the MLT dependency. Fig. 11 shows an example of results with two MLT-L cartographies of flux obtained with this new model near the equator for $\mathrm{E}>2.6 \mathrm{keV}$ electrons on the left and for $\mathrm{E}>8 \mathrm{keV}$ on the right. As already mentioned, this model is valid from $\mathrm{L}=3$ up to $\mathrm{L}=10$ and depends on MLT.

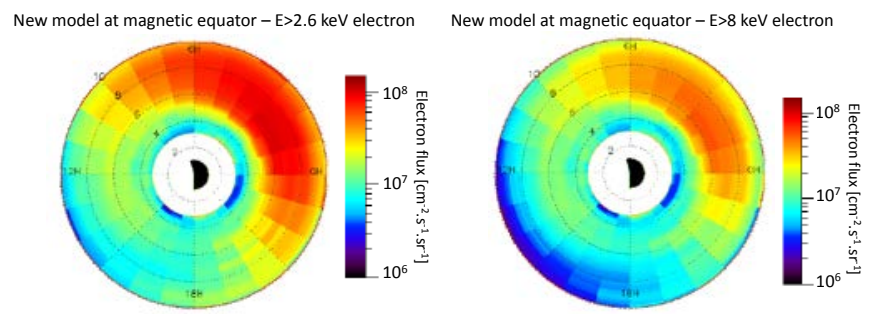

Fig. 11 : Cartographies MLT-L of flux obtained with the new model near equator for $\mathrm{E}>2.6 \mathrm{keV}$ electrons on the left and for $\mathrm{E}>8 \mathrm{keV}$ on the right.

\section{COMPARISON WITH SPM/AE9 MODEL AND DATA}

\section{A. Comparison with AE9/SPM}

The SPM model, part of the AE9/AP9/SPM model distribution can be used to estimate low-energy plasma fluxes [1] [13]. This empirical model is mainly based on POLAR/HYDRA [2] and LANL/MPA [7] data and is valid from $1 \mathrm{keV}$ to $40 \mathrm{keV}$. THEMIS/ESA data have been added in SPM Version 1.2 [13]. In this paper, AE9/SPM V1.5 is used. SPM is not MLT dependent but however be compared to the model described in this paper. Fig. 12 shows comparisons between electrons flux obtained with Mean SPM model (in thick black line), SPM Percentile 99 (in thick grey line) and those provided by the ONERA plasma model (dotted lines) near equator versus radial distance for $\mathrm{E}>2.6 \mathrm{keV}$ (on the top) and $\mathrm{E}>8 \mathrm{keV}$ (at the bottom). The thick red line represents the MLT averaged flux.
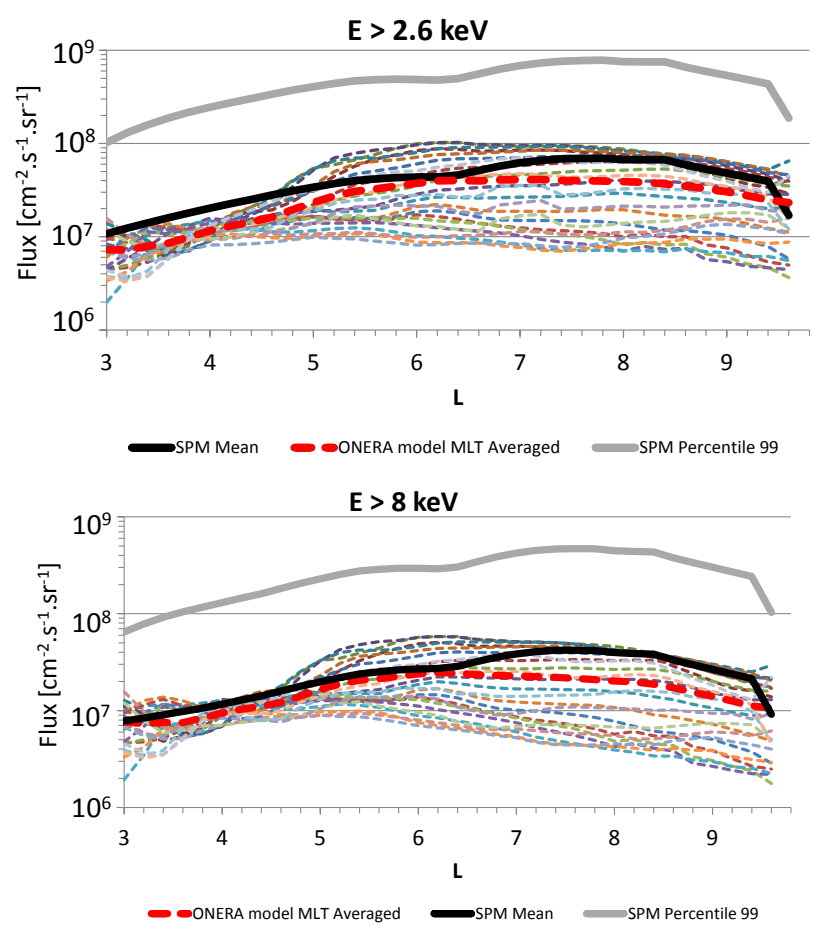

Fig. 12 : Comparisons between electrons flux obtained with SPM Mean model (in thick black line), SPM Percentile 99 (in thick grey line) and those provided by the ONERA plasma model (dotted lines) near equator versus radial distance for $\mathrm{E}>2.6 \mathrm{keV}$ (on the top) and $\mathrm{E}>8 \mathrm{keV}$ (at the bottom).

It is important to note that results from SPM are plotted in terms of the radial distance while those from our new model are plotted in terms of L McIlwain parameter, which can lead to few differences but not significant at the equator.

Comparing these plots, we can observe that flux from SPM are close to MLT averaged flux from ONERA model between $\mathrm{L}=3$ and $\mathrm{L}=6.6$ and close to maximum flux from ONERA model beyond $\mathrm{L}=6.6$.

\section{B. Comparison with Van Allen Probes data}

As mentioned in the section II, due to limited spatial coverage (up to $\mathrm{L}=6$ ) and likely contamination of electron data below $\mathrm{L}=4$, Van Allen Probes plasma data have not been used to develop the model but to validate it. Comparisons between fluxes measured by Van Allen Probes/HOPE data and those calculated with our model have been done with an example of electron fluxes at $8 \mathrm{keV}$ versus MLT at $5.8<\mathrm{L}<6.0$ plotted on Fig. 13. Fluxes measured by THEMIS and POLAR and those calculated with SPM are also represented. These graphs show that fluxes from our model are in line with Van Allen probes measurements. The MLT dependency and flux intensities are very comparable. 
E $>2.6 \mathrm{keV}$
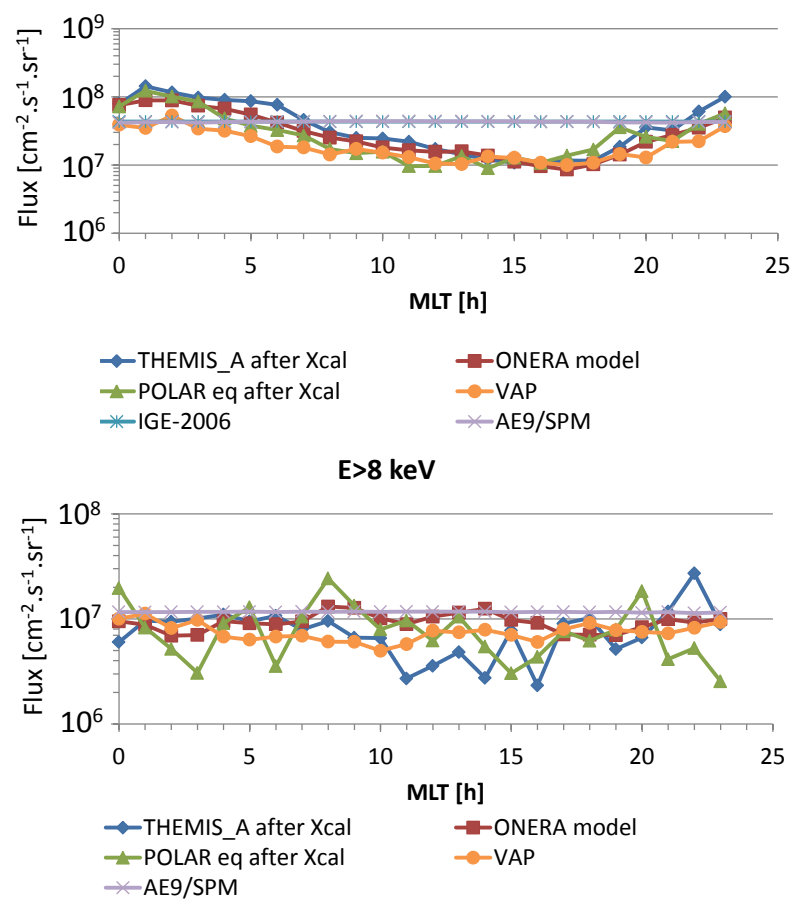

Fig. 13 : Flux versus MLT deduced from several data sets, obtained with AE9/SPM and calculated with the new model for $\mathrm{E}>8 \mathrm{keV}$ electrons and $4.0<\mathrm{L}<4.2$ at the bottom and $\mathrm{E}>2.6 \mathrm{keV}$ and $5.8<\mathrm{L}<6.0$ on the top.

In order to be sure that the model is not only usable near equator, comparison with data has been done outside equator. There are not many data sets at low energy outside equator that's why we have chosen to compare results of the model with POLAR data, even if this data set has been used to develop the model. It allows to control however if the model is well constructed outside equator. Fig. 14 represents $\mathrm{E}>1 \mathrm{keV}$ electron fluxes $\left(\mathrm{cm}^{-2} \cdot \mathrm{s}^{-1}\right)$ along POLAR orbit in 2003 versus $L^{*}$ and equatorial pitch angle $\alpha_{\text {eq }}$ from POLAR data after cross calibration (on the top) and calculated by the new ONERA low-energy model (at the bottom). Let's remember that the ONERA low-energy model is only valid beyond $\mathrm{L}=3$ so only this region is plotted here.

As seen on the figure POLAR orbit sweeps many L-shells at high latitudes (low pitch angles) as well as near the equator (large pitch angles). These plots show that for $\mathrm{L}^{*}$ beyond 5 , fluxes measured by POLAR, taking into account the crosscalibration, are globally coherent with fluxes provided by the model. We can note however that cross-calibrated POLAR fluxes seems to be slightly higher than those of the model but we have to keep in mind that 2003 is a "high year" for fluxes according to the solar cycle while the low-energy plasma model provide mean fluxes with no dependence on the solar cycle.
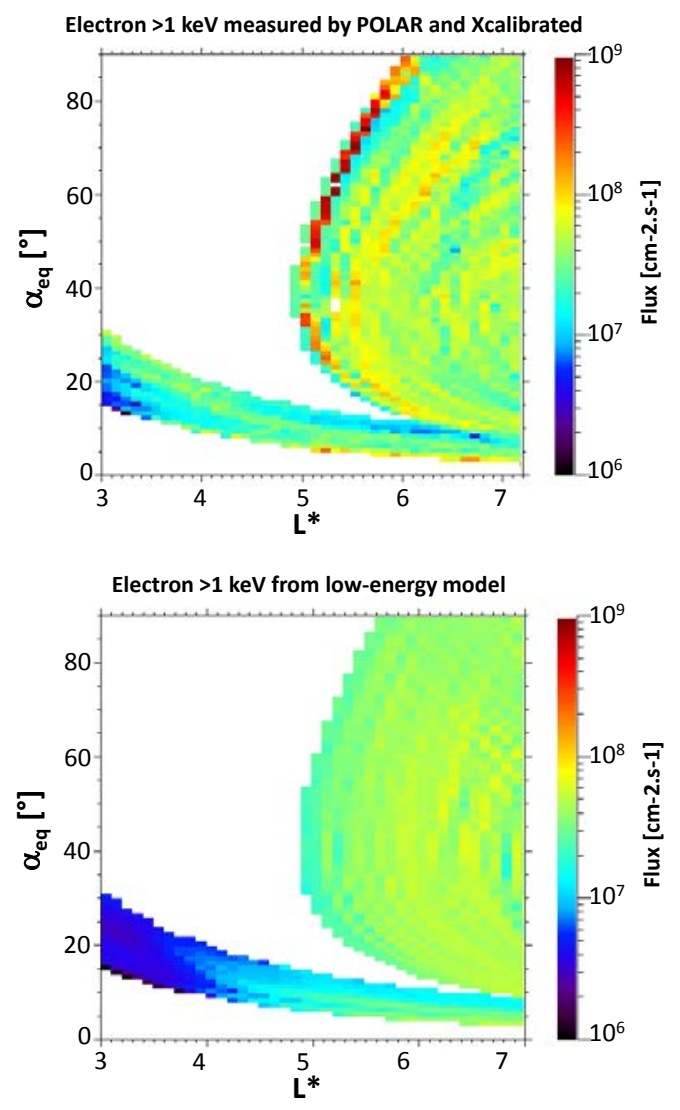

Fig. 14 : E>1 keV electron fluxes $\left(\mathrm{cm}^{-2} . \mathrm{s}^{-1}\right)$ along POLAR orbit in 2003 versus $\mathrm{L}^{*}$ and equatorial pitch angle $\alpha_{\mathrm{eq}}$ from POLAR data after cross-calibration (on the top) and calculated by the new ONERA low-energy model (at the bottom).

\section{IMPLEMENTATION IN GREEN MODEL}

The low-energy electron model described here has been implemented in the version 2 of GREEN (GREEN-V2). Fig. 15 represents the energy and $\mathrm{L}$ coverage of the different models integrated in GREEN-e. A detailed description of GREEN model can be found in Sicard et al., 2018 [3]. The low-energy model is orange on this plot. It replaces AE9/SPM beyond $\mathrm{L}=3$ and is valid from $0.2 \mathrm{keV}$ to $40 \mathrm{keV}$. Extrapolation is done from $30 \mathrm{keV}$ up to $40 \mathrm{keV}$ that is to say the lower energy limit of AE8.

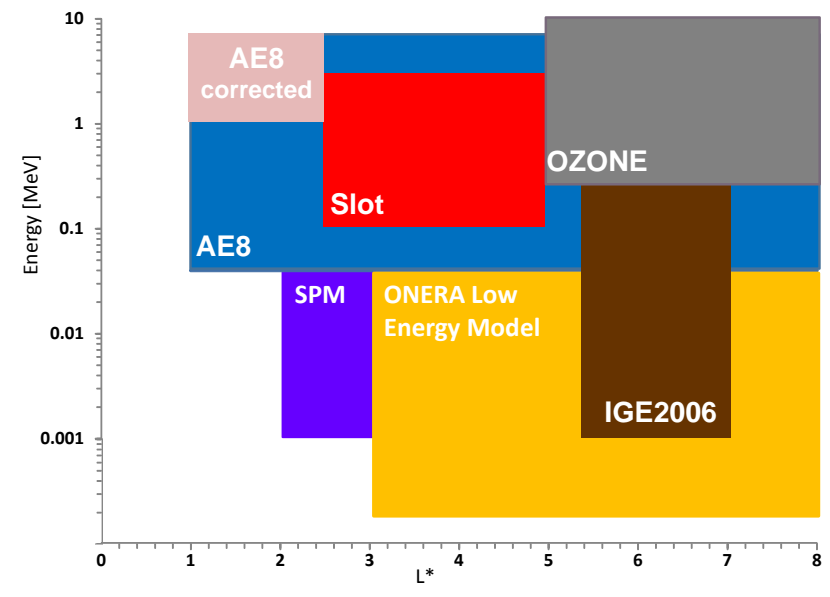

Fig. 15 : Energy and L coverage of the different models integrated in GREEN-e. 
It is important to note than the low energy model is developed in function of L McIlwain parameter while GREEN is based on $\mathrm{L}^{*}$. However a conversion between $\mathrm{L}$ and $\mathrm{L}^{*}$ is done for models to be consistent. Moreover, let's remember that the low energy model is MLT dependent but have no dependence with the solar cycle in contrary to most of the models implemented in GREEN. Not enough data is available to construct a MLT and solar cycle dependent model at low energy.
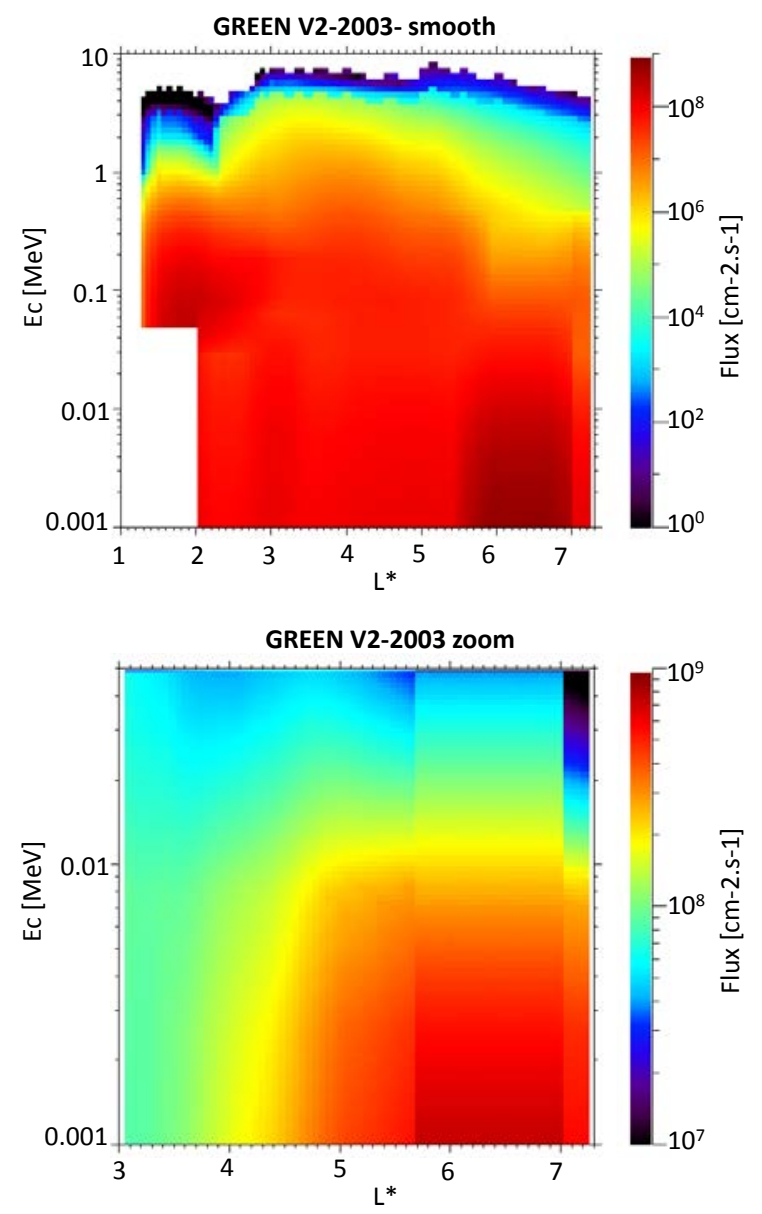

Fig. 16 : Electron flux provided by GREEN-V2 at equator versus energy and $\mathrm{L}^{*}$ in 2003 on the top and a zoom at the bottom

In order to see if the ONERA low energy model is well implemented in GREEN, Fig. 16 shows electron flux provided by GREEN-V2 at equator versus energy and L*, from $1 \mathrm{keV}$ and $10 \mathrm{MeV}$ in 2003 on the top and a zoom of this plot at the bottom. Note that in this plot, the ONERA low-energy model has been averaged in MLT. On the zoom plot (at the bottom) we can see that near geostationary orbit, fluxes provided by IGE-2006 (cf Fig. 15) are slightly higher than those provided by the low energy plasma model described in this paper. This difference can be explained by the fact that IGE-2006 depends on the solar cycle and that 2003 is a year with high fluxes, while the low energy model is not solar cycle dependent and is a mean model.

On these plots, as mention in Sicard et al., 2018 [3], a simple smoothing function has been used (on the top plot of Fig. 16) to smooth existing discontinuities at the interface of "sub- models" implemented in GREEN. Next year, some big efforts will be done to apply more complex smoothing functions.

\section{CONCLUSION}

A new low-energy plasma model has been developed for surface damages calculation. This empirical model is based on NOAA-POES, THEMIS, POLAR and LANL data. Each data set has been analyzed in several dimensions: $L$ between 3 and 10 with a resolution of 0.2 , MLT with a resolution of 1 hour and energy between 0.19 and $30 \mathrm{keV}$ with five energy channels $0.19 \mathrm{keV}, 0.84 \mathrm{keV}, 2.6 \mathrm{keV}, 8 \mathrm{keV}$ and $30 \mathrm{keV}$. This MLT dependent model provides electron from $>0.19 \mathrm{keV}$ to $>30 \mathrm{keV}$ from $\mathrm{L}=3$ up to $\mathrm{L}=10$ and has been compared with AE9/SPM results and validated with Van Allen Probes data. This ONERA low energy model has been implemented in GREEN-e and replace AE9/SPM in this model beyond L=3.

The next step is to develop the same kind of low-energy model for protons and to implement it in GREEN-p. However, only very few good quality protons data are available at low energy $(<100 \mathrm{keV})$, because of contamination by high energy particles, which does not simplify the development of a model.

\section{ACKNOWLEDGMENT}

We acknowledge NASA contract NAS5-02099 and V. Angelopoulos for use of data from the THEMIS Mission,D. Larson and the late R. P. Lin for use of SST data and C. W. Carlson and J. P. McFadden for use of ESA data.

Processing and analysis of the [HOPE, MagEIS, REPT, or ECT] data was supported by Energetic Particle, Composition, and Thermal Plasma (RBSP-ECT) investigation funded under NASA's Prime contract no. NAS5-01072. We acknowledge Harlan Spence (PI) and/or Geoff Reeves (Science Team Lead) for use of ECT data.

We thank the NOAA's National Geophysical Data Center (NGDS) for providing NOAA POES data, the POLAR Hydra team for the use of HYDRA data and the LANL MPA team for the use of MPA data.

\section{REFERENCES}

[1] G. P. Ginet, T. P. O’Brien, S. L. Huston, W. R. Johnston, T. B. Guid, R. Friedel, C. D. Lindstrom, et al., AE9, AP9 and SPM: New models for specifying the trapped energetic particles and space plasma environment, Space Sci. Rev. 179, n 1-4, 579-615, 2013.

[2] J. L. Roeder, M. W. Chen, J. F. Fennell, and R. Friedel, Empirical models of the low-energy plasma in the inner magnetosphere, Space Weather, 3, S12B06, doi:10.1029/2005SW000161, 2005.

[3] A. Sicard, D. Boscher, S. Bourdarie, D. Lazaro, D. Standarovski, and R. Ecoffet : GREEN: the new Global Radiation Earth ENvironment model (beta version), Ann. Geophys., 36, 953-967, https://doi.org/10.5194/angeo-36-953-2018, 2018.

[4] D. S. Evans and M. S. Greer, Polar Orbiting Environmental Satellite Space Environment Monitor - 2 Instrument Descriptions and Archive Data Documentation. NOAA Tech. Memo. 1.4, 2004.

[5] J. P. McFadden, C. W. Carlson, D. Larson, V. Angelopoulos, M. Ludlam, R. Abiad, B. Elliott, P. Turin, M. Marckwordt, The THEMIS ESA plasma instrument and in-flight calibration, Space Sci. Rev, vol 141, 277-302, doi: 10.1007/s11214-008-9440-2, 2008.

[6] J. Scudder, F. Hunsacker, G. Miller, J. Lobell, T. Tawistowski, K. Ogilvie, J. Keller et al., Hydra - A 3 dimensional electron and ion hot plasma instrument for the POLAR spacecraft of the GGS mission, Space Sci. Rev, vol 71, 459-495, 1995.

[7] D. J. McComas, S. J. Bame, B. L. Barraclough, J. R. Donart, R. C. Elphic, J. T. Gosling, M. B. Moldwin, K. R. Moore, and M. F. Thomsen 
(1993), Magnetospheric plasma analyzer: Initial three-spacecraft observations from geosynchronous orbit, J. Geophys. Res., A8, 1345313465, doi:10.1029/93JA00726, 1998.

[8] H. O. Funsten, R. M. Skoug, A. A. Guthrie, E. A. MacDonald, J. R. Baldonado, R. W. Harper et al., Helium, Oxygen, Proton, and Electron (HOPE) Mass Spectrometer for the Radiation Belt Storm Probes mission, Space Sci. Rev, vol 179, 423-484, 2013.

[9] A. Sicard-Piet, S. Bourdarie, D. Boscher, R. H. W. Friedel, M. Thomsen, T. Goka, H. Matsumoto, H. Koshiishi, A new international geostationary electron model: IGE-2006, from $1 \mathrm{keV}$ to $5.2 \mathrm{MeV}$, in Space Weather, vol. 6, no. 7, S07003, doi: 10.1029/2007SW000368, 2008.

[10] D. Payan, A. Sicard-Piet, J.C. Mateo-Velez, D. Lazaro, S. Bourdarie, P. Sarrailh, N. Balcon, Worst case of Geostationary charging environment spectrum based on LANL flight data, Spacecraft Charging Technologies Conference 2014 - Paper 143, https://hal.archives-ouvertes.fr/hal01081993/document, 2014.

[11] J.C. Matéo-Vélez, A. Sicard, D. Payan, N. Ganushkina, N.P. Meredith, I. Sillanpäa. Spacecraft surface charging induced by severe environments at geosynchronous orbit. Space Weather, 16, 89- 106. https://doi.org/10.1002/2017SW001689, 2018.

[12] S. G. Kanekal, D. N. Baker, J. B. Blake, Multisatellite measurements of relativistic electrons: Global coherence, J; Geophys. Res., 106-A12, pp29721-29732, 2001.

[13] W. R. Johnston, T. P. O’Brien, S. L. Huston, T. B. Guild and G. P. Ginet, Recent Updates to the AE9/AP9/SPM Radiation Belt and Space Plasma Specification Model, in IEEE Transactions on Nuclear Science, vol. 62, no. 6, pp. 2760-2764, doi: 10.1109/TNS.2015.2476470, 2015.

[14] A. Sicard-Piet, D. Boscher, D. Lazaro, S. Bourdarie and G. Rolland, A New ONERA-CNES Slot Electron Model, in IEEE Transactions on Nuclear Science, vol. 61, no. 4, pp. 1648-1655, doi: 10.1109/TNS.2013.2293346, 2014. 